\title{
Developing the personal narratives of children with complex communication needs associated with intellectual disabilities: what is the potential of Storysharing ${ }^{\circledR}$ ?
}

Karen Bunning, University of East Anglia, Norwich, NR4 7TJ; Lynsey Gooch East Coast Community Healthcare, Europa House, Nottingham Way, Great Yarmouth, NR30 2SA; Miranda Johnson, Speech \& Language Therapist, Community Health Newham, East London NHS Foundation Trust, E15 4PT.

Running title: Developing personal narratives

\begin{abstract}
Background Sharing personal experience in narrative is challenging for individuals with intellectual disabilities. The aim was to investigate the potential of Storysharing $\AA^{1}$ intervention.

Materials and Methods The study involved eleven pupil-educational supporter dyads at a special school. Storysharing ${ }^{\circledR}$ was implemented over a fifteenweek period. Personal narratives were captured on video pre- and postintervention. The data were analysed for discourse and narrative. Results Significant differences revealed a decline in 'query-answer' sequences and an increase in supporter use of 'prompts'. Post-intervention there were fewer story episodes. Narrative structure showed gains in action sequences leading to climax, and in closing elements, indicating a more complete narrative.

Conclusions The Storysharing $\AA$ intervention appears to be associated with changes to the dyadic, personal narratives illustrating its potential.
\end{abstract}

Keywords: narrative; discourse; communication; intellectual disability

\footnotetext{
${ }^{1}$ Storysharing is an innovative communication method based on personal narrative, which has been developed to support conversations with people who have severe difficulties in communication.
} 


\section{Introduction}

The sharing of stories is critical to the development of social identity and the formation of relationships with others (Grove \& Harwood 2013; Reese et al. 2010a \& b; Soto et al. 2007). The actual telling of stories serves to engage other people in our experiences and views of the world, and contributes to participation (Waller et al. 2006). Oral storytelling has been associated with educational attainment (Curenton et al. 2008; Reese et al. 2010a; Soto et al. 2006; 2007), social inclusion, emotional development and personal empowerment (Atkinson 2004; Hamilton \& Atkinson 2009; Petersen et al. 2010).

Personal narratives centre round a reportable event that has meaning for the teller and listener (Labov 1997). It is the recital of temporally and causally correlated events involving social connotations. Narrative skills develop early in and throughout childhood. By the age of 2-3 years typically developing children have acquired basic narrative skills and are able to link story elements in a sequence containing a central character, topic, or setting (Weismer et al. 2000). Around 4 years they are able to elaborate on the character's facial expressions or body postures and extend a story episode using conjunctions e.g. 'but' and 'because'. From 5 years, children's narrative will usually feature a plot, character development, sequence of events and a problem-resolution process. As language becomes more advanced, so does narrative (Owens 2014), with causal relationships moving towards the story's climax (McCabe \& Peterson 1983).

However, recalling personal experience in narrative is challenging for people with intellectual disabilities (Grove et al. 2011). Their narratives tend to lack coherence and are characterised by: restricted lexical diversity and low productivity generally (Scott \& Windsor 2000); limited sequencing, referencing and knowledge of how to tell a story (Soto et al. 2006); absent relationship marking between characters with poor temporal ordering of events (Grove \& Tucker 2003). There is also a tendency to identify fewer internal responses of characters and to rely on a more restricted system of evaluations (Montague et al. 2001). Capps et al. (2000), using a wordless picture book to stimulate narrative construction, found that children with intellectual disability, whilst able to identify the emotional state of a character, were less likely to identify the causes than their typically developing counterparts. Children using a computer-aided device for expressive communication show a strong reliance on the unaided speaker to drive the narrative (Bailey \& Bunning 2011). Multiple factors may be at play, including inadequate store of vocabulary as well as competence limitations in either the communicator or the conversational partner. 
The social context is critical to the development of language, which includes narrative skills. The child is supported by the 'scaffolding' of more skilled communication partners (Bruner 1983; Vygostky 1978). Tailored to the child's contribution to the telling of a story, scaffolding serves to fill gaps and extend the narrative. Occurring naturally through scaffolded interactions, the child is helped to recall and express ideas (McCabe \& Peterson 1991; Miller \& Sperry 1988). Peterson \& McCabe (1994) found that children's increasing skill in providing contextual information correlated positively with prompt use by the mothers.

Similar social processes have also been endorsed in classroom learning (Barnes 2008), although teacher-initiated questions remain a key feature of many mainstream classroom activities (Hardman, 2008). Studies of dyadic communication between teacher and children with severe intellectual disabilities during English lessons revealed inflated levels of teacher turn occupation and in the use of initiating requests (Bunning et al. 2013; Bunning \& Ellis 2010; Bunning et al. 2010). A shortage of teaching approaches that effectively include children with special educational and language-learning needs was identified in a systematic review of educational pedagogies by Sheehy et al. (2009). However, improvements in teacher effectiveness were associated with activities of personal relevance to the individual and where scaffolding was in place (Sheehy et al. 2009; Rix et al. 2009).

Interventions focused on narrative have attracted growing interest in recent years, despite a lack of specific consideration of oral narrative within the National Curriculum for England and Wales (Grove 2014). Story grammar approaches, where the intervention is primarily controlled by the clinician using visual prompt cards, have been used. For example, Soto et al. (2007) employed storybook reading and retelling, generation of personal stories and fictional story generation. Using such approaches there has been reported gains in the mean length of utterance, vocabulary diversity, (Soto et al. 2007; Isbell et al. 2004; Petersen et al. 2010); morphological markers and grammatical word usage (Soto et al. 2007); causal relationships and sequencing of events (Soto et al. 2007; Petersen et al. 2010); episodic complexity (Petersen et al. 2010); and narrative recollection and personal story production (Spencer \& Slocum 2010).

Multi-sensory storytelling (MSST) draws on the work of Park $(2001 ; 1998)$, who developed a multi-sensory approach to drama, and Fuller (2013) who created 'Bag Books'. It involves the use of objects and sensory stimuli associated with a focal event or sequence of events thereby diminishing dependence on text and words. The idea is to support social engagement by presenting selected stimuli that may be accessed and appreciated by the individual, although variations in the use of such books have been reported 
(ten Brug et al. 2012). Young et al. (2011) employed mothers and familiar professionals in the creation and telling of multisensory stories around sensitive issues such as visiting the dentist, understanding epilepsy and masturbation. Post-intervention interviews indicated improved coping with such issues by the participants. Penne et al. (2012) examined the impact of a MSST workshop on staff communication during an individual story telling task with individuals with profound intellectual and multiple disabilities. However, no change in staff sensitivity and effectiveness was found, leading the authors to suggest a need for specific staff training in how to achieve higher quality interactions during such activities.

Thus it would seem that the supporting role of the conversation partner, e.g. the parent or paid support/educational staff, is germane to the expression of personal narrative. Close observation and sensitive responding to the individual's overt contributions promote social interaction in a process akin to 'attuning' as defined by Griffiths \& Smith (2016). This is an integral part of Storysharing ${ }^{\circledR}$, a newly developed intervention that seeks to develop the personal narratives of individuals who have severe communication difficulties in the context of human interaction. The aim of the current study was to investigate the potential of Storysharing ${ }^{\circledR}$ during interactions between children with complex communication needs associated with intellectual disabilities and their educational supporters, e.g. class teacher, teaching assistant. The research questions were defined in terms of discourse and narrative. The discourse-focused question was: What contributions are made to the shared narrative by the linguistic roles performed by pupil and educational supporter pre- and post- intervention? It was expected that the pupil would make greater contributions to the narrative post-intervention. The narrative-focused question was: How does the narrative vary pre- to post-intervention in terms of structure, completeness and evaluation? It was expected that the joint narratives produced post-intervention would comprise a greater variety of structural elements (e.g. action sequences, climax), be more complete (fewer stories produced in a two-minute sample, which include orientation, action sequences, climax and closure) and demonstrate the use of evaluation (expression of affect through use of speech, vocal and non-vocal gesture).

\section{Methodology}

Design, setting and sample

A small scale, within group study was conducted to evaluate narrative construction by pupils with intellectual disabilities and their educational supporters pre- and post-intervention. The setting was a purpose built, modern, co-educational school catering for 165 children with special educational needs in an urban location of South-West England. The school was divided into Primary and Secondary departments, providing for ages 316 years and a sixth form for ages $16-19$ years. The school had previously 
been awarded Specialist Status for sensory and physical development (UK government recognition of a local centre of excellence in their chosen specialism whereby additional funds were made available under the government's specialist schools programme. This was discontinued in April 2011.), and offered the full National Curriculum as well as additional activities for personal and social growth.

A convenience sample of eleven pupil-educational supporter (teacher or teaching assistant) dyads was established involving two classes (class $1=5$ pupils; class $2=6$ pupils). Table 1 summarises the participant characteristics by class. British Picture Vocabulary Scales (BPVS: Dunn et al. 2009) scores were only available for children who met the baseline requirements. Derbyshire Language Scheme (DLS: Knowles \& Masidlover 1982) scores reflect results of the Rapid Screening Test for Comprehension. Those participants who were at the DLS level $5+(n=4)$ were variously able to recall the details of a story, discuss characters, use story-style language and talk about the main points. Their BPVS scores indicated receptive vocabularies that were approximately within the 6;02-8;04 age range. Those at DLS level 4 $(n=2)$ were able to listen to stories, respond to adult questions, talk about a two-step personal event and retell/act out a simple story. Their BPVS scores were approximately within the 3;08-4;06 age range. The remaining participants were unable to complete the DLS. They either had some ability to tell a simple story through looking, listening and joining in the repetition of familiar parts $(n=3)$, or else were reliant primarily on early stage communication such as directing eye gaze, vocalising, turn-taking and sharing, using objects and sensory stimuli associated with the story $(n=2)$. There were eleven educational supporters comprising teaching assistants and a teacher who led the team. The same educational supporter worked with each child. They were all familiar with the children, having worked with them for a period of 1-2 years. 
Table 1 Summary of sample characteristics: participants only

\begin{tabular}{lllll} 
& $\begin{array}{l}\text { No. of } \\
\text { Participants }\end{array}$ & $\begin{array}{l}\text { Sex } \\
\text { (M:F) }\end{array}$ & Age Range & Communication \\
\hline Class 1 & 4 & $3: 1$ & $12 ; 03-12 ; 09$ & DLS: 5+; BPVS: 6;02-8:04 \\
& 1 & $1: 0$ & & Core vocabulary \\
& & & & \\
Class 2 & 2 & $1: 1$ & $14 ; 10-16 ; 02$ & DLS: 4; BPVS: 3;08-4;06 \\
& 2 & $1: 1$ & & Core vocabulary \\
& 2 & $1: 1$ & & Pre-verbal \\
\hline
\end{tabular}

Note. DLS=Derbyshire Language Scheme (Rapid Screening Test: Knowles \& Masidlover 1982); BPVS=British Picture Vocabulary Scale (Dunn et al. 2009).

\section{Ethics}

Ethical approval was granted by the school ethics committee. Pseudonyms were used to ensure participant anonymity. Project data were made available to members of the research team only.

Project information was supplied to each participant's primary carer who submitted their written consent for their child to participate in the project. In addition, information was presented to the pupils attending each class. Before baseline data collection, the format of the study was explained to the participants. Where appropriate, some pupils were shown the video camera and helped to make a short film of themselves to promote their understanding of the use of video capture in the project. An introductory film was also presented on a laptop computer, explaining that researchers from a university would watch the video recordings as part of the evaluation. Consent forms were then viewed and the participant was asked directly whether they agreed to be filmed. Where an answer of 'yes' was given, filming commenced. Once complete, footage was immediately downloaded to laptop and viewed by the child and staff member. As a final check on informed consent participants were asked 'Can we keep this film?' and 'Is it ok to show this film to some researchers?' When a positive response was recorded, forms were signed. The assent of each pupil was checked prior to each new intervention and filming session throughout the intervention period, and prior to each data collection session. 
Intervention

Storysharing ${ }^{\circledR}$ (www.openstorytellers.org.uk) is an approach to narrative, which aims to enable children and adults with severe communication difficulties to recall and share narratives of personal experience, considered crucial to building a sense of identity and community (Grove \& Harwood 2011). Based on social constructionist models, it draws on the work of Vygotsky (1978), Bruner (1978), Labov (1997), McCabe \& Bliss (2003). Rather than developing a perfect, well-formed narrative, the emphasis is on developing participation in the act of narrating. The approach employs a range of scaffolding strategies to support the process of Storysharing® such that even the person with the most complex communication needs may participate in the retelling of his or her own story (see Grove \& Harwood 2013).

The Storysharing ${ }^{\circledR}$ intervention comprised a systematic, staged framework of collaborative conversational strategies, where questions were minimised in favour of scaffolded prompts with the aim of separating the elicitation of the facts from the social telling of the story. Interventions were planned in conjunction with each class teacher so that Storysharing® sessions were coordinated with the teaching timetable and any individual, behavioural and sensory needs could be accommodated. The intervention was targeted equally at the participant and their educational supporters (e.g. teacher or teaching assistant) as active contributors to the act of storytelling. It was delivered over a 15-week period, facilitated by the project manager who was known to the school. It entailed induction for the supporters lasting one hour, where the principles of Storysharing $\AA$ were explained, questions answered and issues discussed. Following this, once weekly group sessions, each lasting one and a half hours, were carried out, where supporters and participants shared stories of the week and tried out Storysharing® strategies. There were also opportunities for each dyad to work on selected aspects of narration, as well as developing and rehearsing a chosen story of relevance and interest to the participant. In preparation for a Storysharing ${ }^{\circledR}$ session, stories were gathered either from the individual/group or from someone who knew the individual well and recalled the experience. To support this activity, the project leader accompanied the two classes on various school outings. The idea was to help to identify key experiences that would make ideal topics for Storysharing®. The stories needed to involve a high point/climax or departure from routine, with the emphasis placed on the sensory quality of the memory - what was seen, heard, felt, touched, smelt, tasted, and the affective reaction to the experience.

The practical strategies used in the intervention were founded on the requirements of practice and repetition; and the importance of flow, rhythm and musicality in oral storytelling such that teller and audience are attuned and linked into a shared performance. More specifically, the intervention 
encouraged the development and deliberate use of a set of collaborative, conversational strategies to support participation in storytelling, which included:-

- Active listening as an explicit skill, e.g. leaning forward, echoing what speakers say or how they move at key points of the story, giving feedback, e.g. wow! Oh no! really?;

- Modelling: demonstrating how to tell an engaging story through use of pause, stress, pitch and volume shifts, vocal and nonvocal gesture;

- Imitation: eliciting direct imitation of relevant aspects of the telling;

- Repetition: of key phrases in the story, to provide validation and to 'buy time' in the story development;

- Hierarchical prompted sentence completion, e.g. we went to the play.../we went to the p.../we went to...;

- Neutral linking devices, e.g. and... and then... but... so...;

- Use of multimodal communication - gestures, facial expression, body posture, vocalisations, as well as the use of simple voice output communication devices, e.g big mack, and basic props, e.g. key objects from the story and relevant technology (i-pads);

- Participation promotion strategies, e.g. "forgetting" what happened next, getting information deliberately wrong and asking for help, occasional use of clarification questions (was it $x$ or $y$ ?).

A typical session involved participant and educational supporter co-telling a story, which was filmed. Then the film was reviewed by the participant and educational supporter with the Project Leader, identifying the strengths of the co-telling, and what might be changed or developed. A facilitated discussion on the way forward ensued. This more gentle approach was favoured over a more direct approach of setting explicit goals for attainment. Each session was evaluated through completion of narrative notes by the Project Leader. These were reviewed after each session and informed the planning for the following week's session.

Data collection

Video recording of dyadic interactions during Storysharing ${ }^{\circledR}$ were conducted pre- and post-intervention during a 3-week period either before or after the intervention period. Sometimes a more able pupil was invited to be present, as a familiar person to the participant, to alleviate any anxiety expressed by the individual. Space was at a premium in the school setting and therefore filming was carried out in whatever room was available. Typically the pupil and supporter sat close to each other at adjacent angles. The project leader 
operated the camera, a handheld, flip-cam. Initially the pupils were asked to tell a story about themselves with the help of their supporter. Positive feedback and prompts were given by the project leader to encourage participation. If participants were reluctant to share their story, the camera was switched off and the project leader told a story about herself and then used picture cards to help elicit a story from the participant. The camera was switched back on once the participant and supporter were prepared to share their story. The video data were then uploaded to a computer, converted to MP4 format and transferred to DVD.

\section{Sampling, transcription and analysis}

Initially, the two research assistants (RAs) received intensive training in the sampling, transcription and analysis methods over a two-day period. This involved the use of multiple dummy data sets prepared for this purpose. Once the training was completed, the RAs applied their acquired skills and knowledge to the data set. They viewed the video footage for each dyad repeatedly so that the story episodes could be identified. A story episode was defined as a unit of discourse between participant and supporter that referred to a specific event in time and involved a sequence of two or more events or topics. A final check involved the Principal Investigator $(\mathrm{PI})$ reviewing the identified stories. Any discrepancies were discussed until consensus was achieved. The start and end times of each story episode and its narrative features were recorded in an Excel spread sheet. The RA's identified two minutes of the most elaborated story episode, which referred to a specific event in time, had a clear narrative structure of beginning, end, high-point, a climax, reference to feelings or significance. When the most elaborated story lasted for less than two minutes, equal amounts of footage were added before and after it making for similar sample times across the dyads. Restricting the transcription to two minutes reduced the amount of transcription time. This was an important consideration where high usage of non-vocal communication by pupils with severe communication difficulties meant that transcription required repeated viewings of the video recordings at one second intervals in order to produce a faithful transcript. In addition, variable attention levels among the participants meant that the majority of pupils were able to maintain an interactive posture for up to, but no longer than two minutes. It also allowed for direct comparison between pre- and postintervention data and maintained consistency across the participants.

Each identified story episode was transcribed in standard orthography using conventions adapted from von Tetzchner \& Jensen's (1996) notations for augmentative and alternative communication interaction. Unintelligible utterances were checked and re-checked by the RA's and the PI for optimal transcription. A template was used to record the 'story-sharing' data in vertically aligned columns detailing: the time in seconds, the utterance 
number (defined as what a speaker says or signs through use of a word, phrase or sentence; a vocalisation or gesture that appears to have meaning, moves the conversation forward and is interpreted by the supporter; with the boundary being at the end of a sentence, phrase or clause and never more than one complete sentence long without the use of conjunction words); identification of speaker; the dialogue including spoken, verbal, signed and gestured communication.

Completed transcriptions of the two-minute samples were analysed in two ways: discourse and narrative, using prepared coding frameworks developed from work by Carletta et al. (1996) for discourse, and Labov (1997), Norrick (2000), McCabe \& Bliss (2003) for narrative. Discourse analysis focused on the number of turns and utterances used by the interlocutors, i.e. the participant and educational supporter, with the linguistic move-types divided into initiations and responses. Initiations comprised 'oblige-query', 'obligeprompt' and statement'. Responses comprised 'answer', 'repetition' and 'acknowledgement' (see Appendix i for the coding framework). The number of turns and utterances were also calculated for the supporter and participant. The transcripts were reviewed in conjunction with the video footage and move-type codes were assigned to the transcript as appropriate. Narrative analysis involved identifying: the number of topics covered or references made to a specific event in time within the two-minute sample; and the occurrence of structural and evaluative elements (Labov \& Waletzky 1967; Peterson \& McCabe 1983). Unlike the discourse analysis where codes were assigned to each communicative turn occupied by the interlocutors, narrative codes were assigned to the shared narrative. This means that several rows of dialogue may have been assigned one code because they represented the particular element. The code was inserted at the end of such a sequence. Transcribed utterances were reviewed and relevant codes were assigned.

Reliability of coding was addressed through consensus rather than a more formal reliability check. This was due to the complex and frequently idiosyncratic nature of participant communication, which challenged the observers who had no prior knowledge or experience of the individuals as part of the independent evaluation. The two RAs coded the transcriptions independently and then compared the assigned codes. This then highlighted discrepancies and allowed discussion. Where disagreements occurred the footage and transcriptions were referred to the PI for clarification and discussion until agreements could be reached.

Within group, pre- to post intervention changes were computed using the Statistical Package for the Social Sciences (SPSS-18). To explore the discourse balance between participants and supporters and any changes pre- 
to post-intervention, mean scores for turns and utterances, and turn to utterance ratios were established. .To inspect narrative continuity, the number of topics featuring in each sampled narrative were identified. Finally, to investigate the analysis of multiple variables (linguistic move-types; structural and evaluative elements of narrative) in a related, non-normally distributed sample, the non-parametric Friedman's two-way ANOVA (two-tailed) was applied to three sub-sets of the data: 1 . Linguistic move-types used by the participant and the supporter as individual contributors to the narrative; 2 . Structural elements recorded in the shared narrative produced by participant and supporter together; 3 . Evaluative elements used by participant and supporter individually. Because the non-parametric Friedman's ANOVA does not consider separate variables, and so that changes to the different linguistic move-types and structural/evaluative elements of the narrative pre- to postintervention could be inspected, median scores were also calculated.

\section{Results}

- Discourse

Fig. 1 Distribution of turns and utterances for participant and supporter: pre- to post-intervention

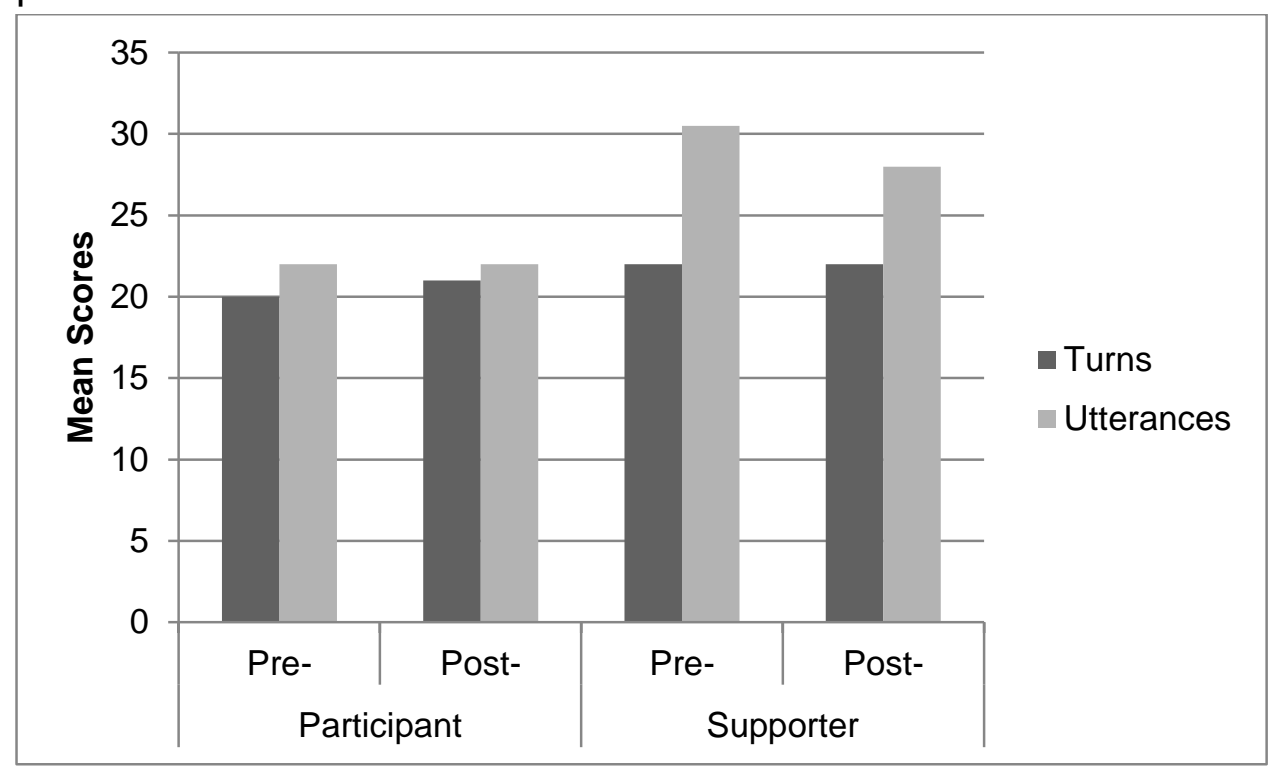

As shown in Fig. 1, the distribution of turns and utterances pre- to postintervention was relatively stable for participants and supporters alike. Supporters had a ratio of utterances to turns of 1.39:1 at baseline, which was slightly lower at the post-intervention point (1.27:1). Participants occupied fewer turns than the supporters generally and had a more even ratio of utterances to turns. 
Use of linguistic move-types showed a significant difference pre- to post intervention for the participants: $X^{2}(5)=53.970, p=<.000$, and the supporters: $X^{2}(5)=30.492, p=<.000$. Summaries of the median scores and standard deviations by participant and supporter are available in Table 2.

Table 2 Distribution of linguistic move-types by supporter and participant: Mean score (standard deviation)

\begin{tabular}{lrrrr} 
& Participant & \multicolumn{3}{c}{ Supporter } \\
\cline { 2 - 5 } $\begin{array}{l}\text { Linguistic move - } \\
\text { type }\end{array}$ & Pre- & Post- & Pre- & Post- \\
& & & & \\
\hline Oblige-query & .00 & .00 & 11.00 & 1.00 \\
& $(.809)$ & $(.467)$ & $(.809)$ & $(.467)$ \\
Oblige- prompt & -- & -- & 1.00 & 9.00 \\
& & & $(5.968)$ & $(8.912)$ \\
Statement & 8.00 & 13.00 & 4.00 & 5.00 \\
& $(5.968)$ & $(9.958)$ & $(7.061)$ & $(6.678)$ \\
Answer & 10.00 & 1.00 & .00 & .00 \\
& $(5.714)$ & $(4.011)$ & $(2.212)$ & $(.505)$ \\
Repetition & .00 & 2.00 & 4.00 & 4.00 \\
& $(1.555)$ & $(2.296)$ & $(5.449)$ & $(4.671)$ \\
Acknowledgement & 3.00 & 2.00 & 4.00 & 2.00 \\
& $(5.061)$ & $(6.708)$ & $(4.696)$ & $(1.328)$ \\
\hline
\end{tabular}

Note. -- $=$ non-occurrence

The frequency of 'Statement' moves by participants made a post-intervention gain and there was a small increase in the use of 'Repetition'. The 'Answer' move declined notably for the participants and 'Acknowledgement' moves dropped slightly for both participants and supporters. However, the most marked change was in the use of 'Oblige-query' moves by supporters, which showed a reduction post-intervention, with a rise in in 'Oblige-prompt' moves. Dialogue excerpts provided here have been selected to illustrate particular characteristics in the narrative as highlighted in the summary median scores. Excerpts 1 and 2 represent pre-intervention and post-intervention dialogue respectively, sampled from the same dyad (S: Supporter; J: Joshua) with linguistic move-types indicated in square brackets. Joshua was one of the more communicatively-able pupils achieving a DLS score of 5+ and a BPVS 
score approximately equivalent to the 6;04 age level. Excerpt 1 shows the line of questioning used by one of the supporters in attempt to elicit the participant Joshua's story about a weekend's outing. It starts at line 4 of the dialogue.

Excerpt 1 Dialogue demonstrating supporter use of 'oblige-query' at baseline (Note. Capitalized word = manual sign; capitalized and underlined $=$ a spoken word with manual sign; -- = pause; ${ }^{* \star *}$ ? = not possible to transcribe)

4. S: WHAT was is it that you did with Adrian? [Oblige-Query]

5. S: did you do any MUSIC or any SINGING? [Oblige-Query]

6. J: singing [Answer]

7. S: WHAT was the singing about? [Oblige-Query]

8. $\mathrm{J}:{ }^{* *}$ ? (unintelligible speech)

9. S: about something that you did every Saturday? [Oblige-Query] 10. J: yeh [Answer]

11.S: yeh, what do you do every Saturday what do you go and eat? [Oblige-Query]

12.J: (laughs) [Acknowledgement]

Excerpt 2 shows the supporter's greater use of 'oblige-prompts' in the retelling of the personal story and the associated growth in Joshua's use of the 'statement' move-types as he completes the stem phrase offered. It starts at line 34 of the dialogue.

Excerpt 2 Dialogue demonstrating increased usage of 'oblige-prompt' postintervention

34. S: and Joshua did some SING-[Oblige-Prompt]

35.J: singing [Answer]

36. S: about M (finger spells M) [Oblige-Prompt]

37. J: MacDonalds [Statement]

38.S: and the pupils LAUGH [Oblige-Prompt]

39. J: laughed [Statement]

40.S: and at the end of the classroom Mrs. Di-- [Oblige-Prompt]

41.J: Dixon [Statement]

42.S: Mrs S [Oblige-Prompt]

43.J: Sellick [Statement]

44. S: Mrs N [Oblige-Prompt]

45. J: Narveth [Statement]

46. S: and ALL THE PU... (mimes counting the children) [Oblige-Prompt]

47.J: --pils clapped [Statement]

48. S: and Joshua (point) FELT [Oblige-Prompt]

49.J: felt happy [Statement] 
- Narrative

The stories shared by the dyads included a range of familiar activities and experiences such as 'coming back to school'; 'watching a film'; 'shopping in a supermarket'; 'eating out', 'cuddles on the blanket'; in the hydro-pool'; 'chocolate'; 'going to the park'; 'playing football on the Wii' and 'bowling'.

Fig. 2 Number of story topics in personal narratives pre- and post-intervention

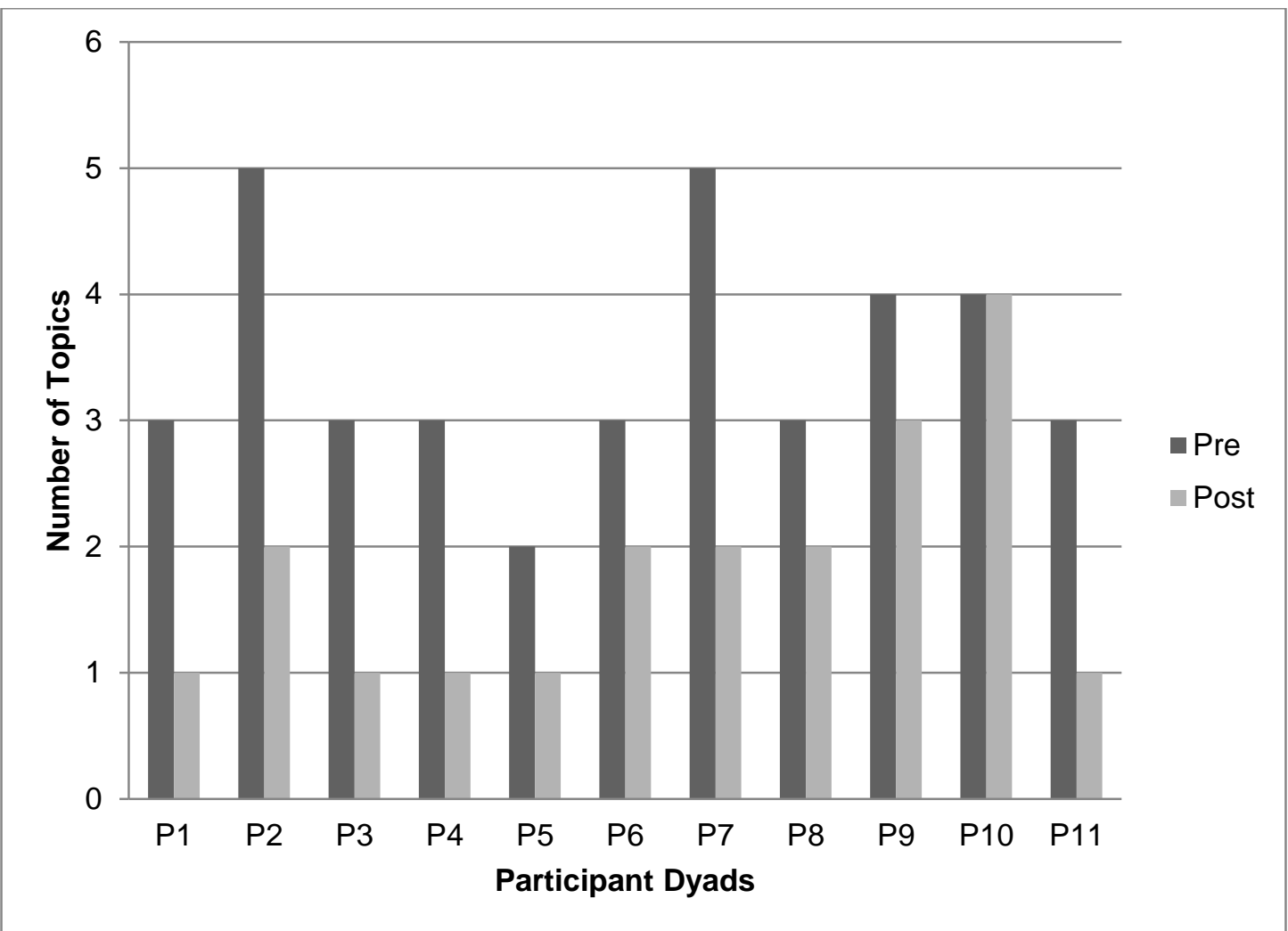

As shown in Fig. 2, post-intervention there was a reduction in the number of topics covered in a two-minute narrative by all the participant dyads, with the exception of participant dyad 10 who maintained four topics at both assessment points.

There was a significant difference in the structural elements of narrative prepost intervention $X^{2}(14)=88.35, p=<0.000$. Table 3 presents the group median scores and standard deviations for the different narrative elements pre- to post-intervention. 
Table 3 Distribution of structural elements pre- to post-intervention: Median score (standard deviation)

\begin{tabular}{lrrrr}
\hline Structural Elements & Pre- & \multicolumn{3}{c}{ Post- } \\
\hline A Attention & .00 & $(.00)$ & .00 & $(.405)$ \\
Abstract & .00 & $(.934)$ & .00 & $(.405)$ \\
\hline B Who & .00 & $(1.009)$ & 1.00 & $(1.502)$ \\
What & .00 & $(.467)$ & 1.00 & $(1.00)$ \\
Where & 1.00 & $(1.183)$ & 1.00 & $(.674)$ \\
When & .00 & $(.302)$ & .00 & $(.647)$ \\
How & .00 & $(1.027)$ & 1.00 & $(.982)$ \\
Description & 2.00 & $(1.446)$ & 1.00 & $(.894)$ \\
Background & 1.00 & $(1.095)$ & .00 & $(.302)$ \\
\hline C Simple actions & 4.00 & $(1.128)$ & 1.00 & $.647)$ \\
Complicating actions & .00 & $(.405)$ & 1.00 & $(.467)$ \\
Climax & .00 & $(.522)$ & 1.00 & $(.302)$ \\
Resolution & .00 & $(1)$ & 1.00 & $(.674)$ \\
\hline D Coda & .00 & $(.302)$ & 1.00 & $(.522)$ \\
Closure & .00 & $(.405)$ & .00 & $(.522)$ \\
\hline
\end{tabular}

Note. $\mathrm{A}=$ Starting-off; $\mathrm{B}=$ Orientation; $\mathrm{C}=$ Action sequences; $\mathrm{D}=$ Closing

As shown in Table 3, B. Orientation (O-) revealed that reference to people (Owho) and things (O-what) and process (O-how) were emphasised more postintervention, whilst 'description' and 'background' decreased; C. Action/event sequences, saw a reduction in 'simple actions' and gains in 'complicating actions', 'climax' and 'resolution'; D. Closing elements were minimal at the pre-intervention point, but 'coda' emerged post-intervention. Excerpts 3 and 4 were sampled from the same dyad (S: Supporter; B: Bradley) pre- and postintervention. Bradley had a core vocabulary and used Makaton signs to express himself. He was working on turn-taking and sharing in paired activities. Coded narrative elements are indicated in square brackets at the end of the relevant sequence of dialogue. Excerpt 3 represents one story episode out of three that were produced pre-intervention within a two-minute 
period. It shows the dominant focus on 'Orientation' elements, specifically 'where' and 'descriptive'. Excerpt 4 contains three dialogue sequences from the single story episode about playing football on the Wii that was produced post-intervention. It illustrates a more complete narrative featuring 'Orientation' in terms of 'who' and 'what'; and 'Action/event sequences' ('simple actions'; 'complicating actions') leading to a 'climax' and 'resolution'.

Excerpt 3 Dialogue demonstrating narrative structure pre-intervention

(Note. Capitalized word $=$ manual sign; capitalized and underlined $=$ a spoken word with manual sign; -- = pause; ${ }^{* * *}$ ? = not possible to transcribe)

1. S: and a few weeks $\underline{A G O}$ Bradley went with Grandad and with Mummy and you went to SEE the ANIMALS (fingerspells $G$ and M) [Starting off: abstract]

2. B: animals

3. $S$ : at the --

4. B: $z 00$

5. S: zoo [Orientation: where]

6. S: was it good?

7. B: yeh

8. S: it was really good fun [Orientation: descriptive]

Excerpt 4 Dialogue demonstrating narrative structure post-intervention (break in excerpt is indicated by

4. S: when Bradley goes to play he has to put his - BOOTS

5. B: bu (vocalises approximation of 'boots)

6. S: BOOTS on (mimes doing up laces)

7. B: BOOTS (mimes undoing/redoing loop fastener on shoes) [Orientation: what]

8. S: and has to do lots of - - STRETCHES

9. B: stretches yeh [Simple Actions]

10.S: Bradley likes to PLAY with his friend Barry Mills [Orientation: who]

32. S: BRADLEY LIKES to play with MUMMY on the Wii (mimes using the Wii) [Orientation: who]

33. B: weh (approximation of 'Wii')

34. S: on the Wii

35.S: on the Nintendo Wii [Orientation: what]

41.S: and RUNNING and kicking the ball and then he did a HEADER- -

42. B: (vocalisation 'beh')

43. S: what did you do?

44. B: HEADER (mimes heading the ball)

45. S: HEADER! [Action/event sequences: complicating actions]

46. S: and you got a - 
47. B: geh (approximation of 'goal')

48. S: YEAH (arms in the air as if celebrating) [Action/event sequences: climax]

49. S: and Bradley was given a -

50. B: meh (approximation of medal)

51. S: MEDAL

52. B: Bradley is hoping that his team will win the CUP

53. B: keh (approximation of 'cup') [Action/event sequences: complicating actions]

54.S: and he will say HOORAY HOORAY (shakes arms in air as if celebrating)

55. B: gaaaa (approximation of 'goal' with elongated vowel) [Action/event sequences: climax]

56. S: and everyone will CLAP (does action of clapping) [Action/event sequences: resolution]

\section{Discussion}

With regard to discourse, turn occupation and utterances remained at similar levels before and after intervention for the participants and supporters.

Linguistic move-types varied significantly pre- to post-intervention for both the participants, who used fewer answers and more statements, and the supporters, who used fewer obliging questions and more prompts. In terms of the narrative, there were fewer story episodes in the two-minute sample produced post-intervention, demonstrating improved topic maintenance. Structural elements of the narratives were significantly different pre- to postintervention.

\section{Discourse}

The fairly even turn distribution between supporter and participant appears to be consistent with Liboiron \& Soto (2006), who found turn distribution to be evenly matched during a shared storybook reading with a child using a computer-aided communication device. The extensive use of 'oblige-queries' by the supporters pre-intervention, are similar to that reported by Liboiron \& Soto (2006), which they attribute to promoting metalinguistic skills, considered critical to emergent reading skills and comprehension. It also resonates with findings from studies of classroom talk (e.g. Bunning et al. 2013; Bunning \& Ellis 2010; Bunning et al. 2010). Supporter use of questions at baseline was probably a strategy for engaging the participant with limited communication skills. The Storysharing $®$ intervention demonstrated alternative ways of cueing and supporting the child to share a story or personal narrative. For example the reduction in supporter initiated 'queries' post-intervention is probably associated with a rise in their use of 'prompts'. The greater usage of 'scaffolding' (after Bruner 1983; Vygostky 1978) may also be related to the growth in 'statement' use by the participants, which would be consistent with 
findings in a similar study (Peterson \& McCabe 1994). Of course, the participants in the current study all had restricted communication skills with a strong reliance on communication methods other than speech, e.g. eye gaze, vocal and facial gesture, body language. Repeated rehearsal of the storytelling episode offered a number of opportunities for the educational supporter and pupil to develop their shared narratives. For the educational supporters there was the opportunity to familiarise with the individual's communication repertoire, to observe closely their expressive behaviours and to recognise contributions to the narrative interaction. Through a process of tuning-in, the educational supporter would have been helped to select the most relevant forms of scaffolding for the individual pupil. This resonates the attuning theory proposed by Griffiths \& Smith (2016) where agency and social coordination are shared within the partnership. Furthermore, the practice associated with the repeated exercise of Storysharing ${ }^{\circledR}$ is likely to have promoted feelings of confidence in the supporter's use of facilitation strategies. For the pupil, the process of going through the same story on a number of occasions will have helped them in the recall and expression of ideas (McCabe \& Peterson 1991; Miller \& Sperry 1988).

Narrative completion and structure

The poor level of topic maintenance recorded at baseline is consistent with Montague et als (2001) study, where pupils with intellectual disabilities provided significantly shorter episodes on a story retelling task than their typically developing peers. It is possible that deficits in the productivity, fluency and lexical diversity of the participants have affected their narrative development as evidenced by Scott \& Windsor (2000). Additionally, prior to intervention, supporters may have been unaware of or inexperienced in how to maintain the story topic by using conversational strategies such as neutral linking devices, e.g. 'and'. The reduction in the number of topics postintervention is indicative of an enhanced ability to maintain topics. This may be associated with the deliberate use of conversation strategies by the supporter to extend and maintain the narrative, such as the use of neutral linking devices (e.g. 'and'), as well as other stem phrase prompts (e.g. 'and you go a......'). Through use of such strategies, episode continuity was encouraged and the more typical communications associated with this population, characterised by brief exchanges and frequent breakdowns, were diminished.

Narrative structure at baseline was limited in comparison to the postintervention output. The supporter and participant appeared to focus on the 'orientation' aspects of the story, such as description, and omitted action sequences leading to a climax and resolution. Through learning about narrative structure and the rehearsal of selected aspects of a personal story, the supporters and participants appear to have engaged in a more 
comprehensive structuring of focal topics (Grove \& Harwood 2012).

Opportunities for frequent story formulation during the intervention is likely to have helped story construction and production, which is similar to Isbell et al. (2004) who, post-intervention, reported an increase in the use of formal endings, theme identification, setting, moral of the story amongst typically developing 3-5-year olds, and Soto et al. (2007) who reported increased story complexity, use of resolutions, temporal connectives, and sequentially-related and coordinated events. The Storysharing ${ }^{\circledR}$ intervention exposed the educational supporters to alternative ways of facilitating storytelling, e.g. to move away from simple transaction of information through question-answer sequences, and to increase the use of 'action sequences' for building the narrative.

\section{Limitations}

As a small scale study, the results provide an illustration of potential impacts associated with a narrative intervention that targets the 'Storysharing' partnership. There was no control condition and therefore any changes recorded cannot be attributed directly to the intervention. Data collection was conducted in the familiar setting of the school and therefore ambient noise levels were variable. Extra individuals were present sometimes as naïve listeners, to help ease participant anxiety and encourage natural interactions; however, their presence and occasional contributions to the recorded narrative was a potential factor of influence. This was also true of the camera operator who intervened occasionally when the supporter appeared to be having trouble getting started. Camera reactivity was not specifically addressed and future research should consider excluding early footage, where reactivity is more likely. Unfortunately, the microphone in use was not always sensitive to the quieter voices of the participants making transcription difficult. A body worn microphone might circumvent this issue.

\section{Conclusions and Implications}

Personal stories are relevant to all human beings regardless of language ability. The Storysharing ${ }^{\circledR}$ intervention appears to have been a catalyst for change in the way personal stories were told. It has the potential to enable individuals with limited communication skills to join with supporters in the retelling of experiences and ideas. Further research is needed to explore the possible benefits and applications of Storysharing ${ }^{\circledR}$ with people who have complex communication needs associated with intellectual disabilities.

\section{Acknowledgements}

The authors would like to acknowledge the contribution of the pupils and educational supporters in sharing their personal narratives. The Storysharing® project was supported by the Paul Hamlyn Foundation. 


\section{Conflict of interest}

No conflicts of interest.

\section{References}

Atkinson, D. (2004) Research and empowerment: Involving people with learning difficulties in oral and life history work. Disability and Society 19, 691702.

Bailey, P. \& Bunning, K. (2011) Narrative construction by an aided speaker: a pilot study. Journal of Assistive Technologies 5,199-213.

Barnes, D. (2008) Exploratory talk for learning. In: Exploring Talk in Schools (Eds. N. Mercer \& S. Hodgkinson), pp. 1-15, London, Sage.

Bruner, J. (1978) The role of dialogue in language acquisition. In: The Child's Concept of Language (eds. A. Sinclair, R. Jarvelle \& W. Levelt), pp. 241-256. New York, Springer - Verlag.

Bunning, K., Smith, C., Kennedy, P. \& Greenham, C. (2013) Examination of the communication interface between pupils with severe to profound and multiple intellectual disability and educational staff during structured teaching sessions. Journal of Intellectual Disability Research 5, 39-52.

Bunning, K. \& Ellis, M. (2010) A Preliminary Investigation into Communication in the Special Needs Classroom during Key Stage 3 English Lessons. Child Language Teaching and Therapy 26, 180-194.

Capps, L., Losh, M. \& Thurber, C. (2000) 'The frog ate the bug and made his mouth sad': Narrative competence in children with autism. Journal of Child Psychology 28, 193-204.

Carletta, J., Isard, A., Isard, S., Kowtko, J., Doherty-Sneddon, G. \& Anderson, A. (1996) HCRC Dialogue Structure Coding Manual. HCRC TR-82. Human Communication Research Centre, University of Edinburgh.

Curenton, S., Jones Craig, M. \& Flanagan, N. (2008) Use of decontextualized talk across story contexts: How oral storytelling and emergent reading can scaffold children's development. Early Education \& Development 19, 161-187. Dunn L. M., Dunn L. M. Sewell \& Styles. (1997) The British Picture Vocabulary Scale, Second Edition. NFERNelson, UK. Fuller, C. (2013). Multi sensory stories in story packs. In Using Storytelling to Support Children and Adults with Special Needs (Ed. N. Grove), pp.72-77. London, Taylor \& Francis.

Griffiths, C. \& Smith, M. (2016) Attuning: A communication process between people with severe and profound intellectual disability and their interaction partners. Journal of Applied Research in Intellectual Disabilities 29, 124-138. Grove, N. (2014) Personal oral narratives in a special school curriculum: an analysis of key documents. British Journal of Special Education 41, 6-24. Grove, N. \& Harwood, J. (2013) Storysharing: Personal narratives for identity and community. In: Using Storytelling to Support Children and Adults with Special Needs (ed. N. Grove), pp. 102-110. London, Taylor \& Francis. Grove, N. \& Tucker, S. (2003) Narratives in manual sign by children with 
intellectual impairments. In: Augmentative and Alternative Communication: Developmental Issues (eds. S. von Tetzchner \& N. Grove), pp. 229-255. London, Whurr Wiley.

Grove, N. (2011) Identity and friendship through sharing stories, Lost for Words, Openstorytellers.

http://www.city.ac.uk/_data/assets/pdf_file/0005/96701/Session-Grove.pdf, (accessed on 10 August 2015).

Grove, N., Bunning, K., Porter, J. \& Olsson, C. (1999) See what I mean: Interpreting the meaning of communication by people with severe and profound intellectual disabilities. Journal of Applied Research in Intellectual Disabilities 12, 190-203.

Grove, N. \& Harwood, J. (2011) Storysharing in Somerset final report. http://www.openstorytellers.org.uk/. (accessed on 10 August 2015). Hamilton, C. \& Atkinson, D. (2009) A story to tell: Learning from life stories of older people with intellectual disabilities in Ireland. British Journal of Learning Disabilities 37, 316-322.

Hardman, F., Smith, F. \& Wall, K. (2005) Teacher pupil dialogue with pupils with special educational needs in the National Literacy Strategy. Educational Review 57, 299-316.

Hughes, D. (2004) An attachment based treatment of maltreated children and young people. Attachment and Human Development 6, 263-78.

Isbell, R., Sobol, J. Lindauer, L. \& Lowrance, A. (2004) The effects of storytelling and story reading on the oral language complexity and story comprehension of young children. Early Childhood Education Journal 32, 157163.

Knowles, W. \& Masidlover, M. (1982) The Derbyshire Language Scheme. http://www.derbyshire-language-scheme.co.uk. (accessed on10 August 2015).

Labov, W. (1997) Some further steps in narrative analysis. Journal of Narrative and Life History 7, 395-415.

Labov, W. \& Waletzky, J. (1976) Narrative analysis: oral versions of personal experience. In: Essays on the Verbal and Visual Arts (ed. J.Helm), pp. 12-44. Seattle WA, University of Washington Press.

Liboiron, N. \& Soto, G.(2006) Shared storybook reading with a pupil who uses alternative and augmentative communication: A description of scaffolding practices. Child Language Teaching and Therapy 22, 69 -95.

McCabe, A. \& Petersen, C. (Eds.) (1991) Developing Narrative Structure. Hillsdale NJ, Erlbaum.

McCabe, A. \& Bliss, L. (2003) Patterns of Narrative Discourse. Boston MA, Pearson Education.

Miller, P. \& Sperry, L. (1988) Early talk about the past. Journal of Child Language 15, 293-315.

Montague, M. Maddux, C.D. \& Dereshiwsky, M.I. (1990) Story grammar and comprehension and production of narrative prose by pupils with learning 
disabilities. Journal of Learning Disabilities 23,190-197.

Norrick, N. (2000) Conversational Narrative in Everyday Talk. Amsterdam, John Benjamins.

Owens, R. (2008) Language Development: An Introduction. Boston MA, Pearson.

Openstorytellers, Living through story. http://www.openstorytellers.org.uk. (accessed on 10 August 2015).

Park, K. (2001) Oliver Twist: an exploration of interactive storytelling and object use in communication. British Journal of Special Education 28, 18-23.

Park, K. (1998) Dickens for all: inclusive approaches to literature and communication with people with severe and profound learning disabilities.

British Journal of Special Education 25, 114-118.

Penne, A., Brug, A., Munde, V., Van der Putten, A. Vlaskamp, C. \& Maes, B. (2012) Staff interactive style during multisensory storytelling with persons with profound intellectual and multiple disabilities. Journal of Intellectual Disability Research 56, 167-178.

Petersen, D., Gillam, S., Spencer, T. \& Gillam, R. (2010) The effects of literate narrative intervention on children with neurologically based language impairments: An early study. Journal of Speech, Language and Hearing Research 53, 961-981.

Peterson, C., \& McCabe, A. (1983). Developmental psycholinguistics: three ways of looking at a child's narrative. Plenum Press, New York.

Peterson, C. McCabe, A. (1992) Parental styles of narrative elicitation: effect on children's narrative structure and content, First Language 12, 299-321.

Reese, E., Suggate, S., Long, J. \& Schaughency, E. (2010a) Children's oral narrative and reading skills in the first three years of reading instruction. Reading and Writing 23, 627-644.

Reese, E., Yan, C., Jack, F. \& Hayne, H. (2010b) Emerging identities: Narrative and self from early childhood to early adolescence. In: Narrative Development in Early Adolescence: Creating the Storied Self (eds. K. McLean \& M. Pasupathi), pp. 23-43. New York, Springer.

Rix, J., Hall, K., Nind, M., Sheehy, K. \& Wearmouth, J. (2009) What pedagogical approaches can effectively include children with special educational needs in mainstream classrooms? A systematic literature review. Support for Learning 24, 86-94.

Sheehy, K., Rix, J., Collins, J., Hall, K., Nind, M., \& Wearmouth, J. (2009) A systematic review of whole class, subject based, pedagogies with reported outcomes for the academic and social inclusion of pupils with special educational needs in mainstream classrooms. EPPI-Centre, Social Science Research Unit, Institute of Education, University of London, UK.

Scott, C. \& Windsor, J. (2000) General language performance measures in spoken and written narrative discourse of school age children with language learning disabilities. Journal of Speech, Language and Hearing Research 43, 324-339. 
Soto, G., Hartmann, E. and Wilkins, D. P. (2006) Exploring the Elements of Narrative that emerge in the Interactions between an 8-Year-Old Child who uses an AAC Device and her teacher. Augmentative \& Alternative Communication 22, 231-241.

Soto, G., Yu, B. \& Henneberry, S. (2007) Supporting the development of narrative skills of an eight-year old child who uses an augmentative and alternative communication device. Child Language Teaching and Therapy 23, 27-45.

Ten Brug, A., can der Putten, A., Penne, A., Maes, B. \& Vasclamp, C. (2012) Multi-sensory storytelling for persons with profound intellectual and multiple disabilities: an analysis of the development, content and application in practice. Journal of Applied Research in Intellectual Disabilities 25, 350-359. Vygotsky, L. S. (1978) Mind in Society: The Development of Higher Psychological Processes. Cambridge, MA, Harvard University Press. Von Tetzchner, S. \& Jensen, M.H. (1996) Augmentative and Alternative Communication: European Perspectives. London, Whurr Publishers. Waller, A., O'Mara, D., Tait, L., Booth, L., Brophy-Arnott, B., \& Hood, H. (2001) Using written stories to support the use of narrative in conversational interactions: Case study. Augmentative and Alternative Communication 17, 221- 239.

Young, H., Fenwick, M., Lambe, L. \& Hogg, J. (2011) Multi-sensory story telling as an aid to assisting people with profound intellectual disabilities to cope with sensitive issues: A multiple research methods analysis of engagement and outcomes. European Journal of Special Needs Education $26,127-142$. 


\section{Coding Frameworks}

Appendix i

\section{- Discourse structure}

\begin{tabular}{ll}
$\begin{array}{l}\text { Coding } \\
\text { Item }\end{array}$ & Definition \\
\hline Turn & $\begin{array}{l}\text { Boundaries are indicated by speaker change and are counted } \\
\text { separately in the analysis. A turn may be non-vocal if it clearly } \\
\text { contributes to the moving forward of the conversation, e.g. a } \\
\text { laugh, gaze, hand movement, to which the other partner } \\
\text { responds. }\end{array}$ \\
Utterance & $\begin{array}{l}\text { What a speaker says, signs or records on a communication } \\
\text { aid, this can be a word, a phrase or a sentence. It is never } \\
\text { more than one complete sentence (a segment of speech } \\
\text { containing a subject \& predicate). In the case of a nonverbal } \\
\text { child, a vocalisation or gesture that appears to have meaning, } \\
\text { moves the conversation forward, is interpreted by the support } \\
\text { worker. }\end{array}$
\end{tabular}

- Linguistic move-types

\begin{tabular}{ll} 
Move-type & Definition \\
\hline Oblige-Query & $\begin{array}{l}\text { Questions/instructions which demand a response from the } \\
\text { other person. }\end{array}$ \\
$\begin{array}{l}\text { Oblige- } \\
\text { Prompt }\end{array}$ & $\begin{array}{l}\text { Stem phrases, either spoken or gestured, that are used to } \\
\text { trigger a response from the other person. }\end{array}$ \\
Statement & $\begin{array}{l}\text { Provision of information that furthers the narrative, but does } \\
\text { not demand a response necessarily from the other person. }\end{array}$ \\
Answer & $\begin{array}{l}\text { Provide information in answer to a question or an instruction } \\
\text { from the conversational partner. }\end{array}$ \\
Repetition & $\begin{array}{l}\text { Words or phrases, gestures or signs, which repeat a } \\
\text { preceding utterance, including those earlier in the dialogue. }\end{array}$ \\
Acknowledge & $\begin{array}{l}\text { Indicates that something has been heard or seen, but falls } \\
\text { short of definite answer, e.g. use of back channels to indicate } \\
\text { acknowledgement, 'yeh'. No new content is added. }\end{array}$
\end{tabular}


- Narrative Elements

\begin{tabular}{|c|c|}
\hline Starting off & $\begin{array}{l}\text { The introductory phase of the narrative, which attracts attention and } \\
\text { informs the audience }\end{array}$ \\
\hline $\begin{array}{l}\text { Attention } \\
\text { getter }\end{array}$ & $\begin{array}{l}\text { Uses movement, vocalisation, speech object, instrument, gesture to } \\
\text { attract attention of the audience (rather than to tell the story per se), } \\
\text { e.g. guess what; }\end{array}$ \\
\hline Abstract & $\begin{array}{l}\text { An introductory statement which that reports the entire sequence of } \\
\text { events of the narrative. Answers the potential question "what is this } \\
\text { about?" }\end{array}$ \\
\hline Orientation & $\begin{array}{l}\text { Information which starts the story off: gives information on the time, } \\
\text { place of the events of a narrative, the identities of the participants. } \\
\text { Answers the potential questions "Who, what, when, where, how?" }\end{array}$ \\
\hline O-Who & Reference to people or characters \\
\hline O-Where & Reference to place \\
\hline O-When & Reference to time, date, \\
\hline O-What & Reference to things - possessions \\
\hline O-How & $\begin{array}{l}\text { Elaborations that add a detail that describe how something was } \\
\text { done }\end{array}$ \\
\hline Descriptives & $\begin{array}{l}\text { Statements which describe what was seen, touched, heard, tasted, } \\
\text { smelled - elaborating what we know. }\end{array}$ \\
\hline Background & $\begin{array}{l}\text { Background information: e.g. we used to go to the cafe every Friday } \\
\text { night... }\end{array}$ \\
\hline $\begin{array}{l}\text { Action /event } \\
\text { sequences }\end{array}$ & $\begin{array}{l}\text { The phase of the narrative which builds up to the climax if there is } \\
\text { one. Some narratives consist only of a sequence of actions. }\end{array}$ \\
\hline $\begin{array}{l}\text { Simple } \\
\text { actions }\end{array}$ & $\begin{array}{l}\text { Actions which follow one another but are not organised round a } \\
\text { climax; single references to an activity, e.g. shopping }\end{array}$ \\
\hline $\begin{array}{l}\text { Complicating } \\
\text { actions }\end{array}$ & Actions which are clearly leading up to the climax \\
\hline Climax & $\begin{array}{l}\text { The reportable event, which is at the heart of the narrative. Often } \\
\text { signalled by increased nonverbal behaviours, pauses, emphasis. } \\
\text { This event is the reason for telling the story, and is the one with the } \\
\text { most impact on the views, feelings and actions of the narrator. }\end{array}$ \\
\hline Resolution & $\begin{array}{l}\text { Reference to events that follow the climax, providing a result or } \\
\text { resolution. }\end{array}$ \\
\hline
\end{tabular}

Closing

Coda A final clause which returns the narrative to the time of speaking, e.g. that's my story...that's it. 
Closing

Nonverbally, shows clear awareness of end of story, e.g. looks signals down, drops hands if signing, gesture of handing over, looks to listener, vocalisations 